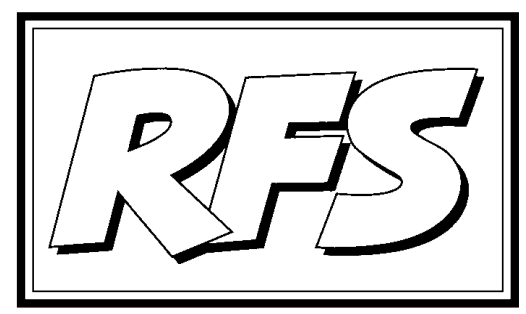

Revista de Fomento Social, 58 (2003), 317-342

\title{
Responsabilidades familiares y estabilidad en el empleo de los trabajadores
}

\section{- Pilar NÚÑEZ-CORTÉS CONTRERAS y Ma J osé LÓPEZ ÁlVAREZ * \\ (Palabras clave: Estabilidad laboral, Vida familiar, Protección estabilidad. Key words: Stability, Family life, Protection in employment)}

\section{Introducción: planteamiento de la cuestión}

El trabajador que asume compromisos en el ámbito familiar, tiene como preocupación primera determinar las posibles repercusiones que vayan a derivarse para su relación laboral y, en particular, si éstas pueden llegar al extremo de poner en juego la pervivencia de su contrato de trabajo. No se trataúnicamente delas decisiones improcedentes que, en un momento dado, pueda adoptar el empresario en estas circunstancias o de las reticencias que manifieste ante ciertas concesiones. En muchas ocasiones, el principal obstáculo que encuentra el trabajador para la armonización de ocupaciones

\footnotetext{
* Profesoras de Derecho del trabajo (Universidad Pontificia Comillas, Madrid).
} 
tan dispares proviene simplemente de la inexistencia de un marco propicio para ello que garantice, por ejemplo, la reincorporación a la vida profesional activa tras períodos de dedicación más intensa a la familia. Por otra parte dicho marco debecontribuir a atenuar los efectos negativos que produceuna desvinculación prolongada de la empresa 0 atender, desde una perspectiva más amplia, al carácter cuasi-permanente que casi siempre presentan las obligaciones familiares y exigir, más allá de la protección que se dispensa en momentos puntuales, una especial flexibilidad en todos los ámbitos de la relación laboral ${ }^{1}$.

La conservación del puesto de trabajo así entendida presupone, por tanto, no sólo la continuidad formal del contrato vigente, sino igualmente el mantenimiento de unas condiciones satisfactorias en el desempeño de la prestación laboral, incluidas unas perspectivas razonables de promoción profesional, o lo que es lo mismo, se trata de evitar que las cargas familiares se conviertan en un factor decisivo para el estancamiento, cuando no el abandono, del trabajador. La búsqueda de esta estabilidad constituye, pues, el trasfondo o si se quiere, el objetivo último de las políticas de conciliación, a pesar de lo cual ha sido escasa la atención que, hasta fechas recientes, ha recibido por parte del legislador, más preocupado, al menos en apariencia, por articular medidas destinadas a la satisfacción directa de otros bienes jurídicos tales como la salud e integridad física de la madre y el hijo, la protección de la familia o la igualdad de la trabajadora. En buena parte, ello ha de achacarse a los patrones sociales imperantes durante mucho tiempo que, al relegar a la mujer a las tareas domésticas, marcaron un modelo de regulación laboral en el que estas cuestiones recibirían un tratamiento residual, ceñido al hecho biológico de la maternidad o con disposiciones que, incluso, trataban de excluir frontalmente la presencia de la mujer en el trabajo durante la época de nacimiento y crianza de los hijos. Pero lo cierto es que, coincidimos con Cruz Villalon ${ }^{2}$ en que, como resultado de esta tradición normativa, se ha terminado por configurar un entorno productivo

1 Cfr. P. Charro Baena-S. Herraiz Martín, (1998), p. 535 quienes denuncian el escaso número de disposiciones que se ocupan en el ámbito laboral de las responsabilidades familiares así como el alcance limitado de las mismas, centrado casi exclusivamente en el momento del nacimiento del hijo. Para una visión crítica, cfr. editorial sobre "Familia y Trabajo" en Revista de Fomento Social (2002), no 225, vol. 57.

2 J. CRUz Villalón (1999), p. 72 en el que señala cómo, todavía hoy, la incorporación plena de la mujer al mercado de trabajo se realiza a expensas de renunciar a formar una familia estable o asumir una "doble jornada" dentro y fuera del ámbito familiar. 
dirigido a trabajadores "liberados" de responsabilidades familiares y en el que se hace extremadamente complicado compatibilizar a medio plazo la vida personal y profesional.

\section{Fórmulas arbitradas por el legislador para la protección de la estabilidad en el empleo de los trabajadores con responsabilidades familiares}

En este contexto, tres grandes etapas reflejan la evolución seguida por el legislador y pueden ilustrar las dificultades que actualmente se plantean para articular iniciativas eficaces que den respuesta a este problema.

\subsection{Los orígenes de la regulación normativa: la Ley de 1900}

Un primer momento cabe situarlo con ocasión de la aparición del primer núcleo de legislación obrera a comienzos del siglo XX. El Derecho del Trabajo se encuentra todavía en fase embrionaria, por lo que las intervenciones estatales en el ámbito social son puntuales, destinadas principalmente a atajar los abusos sangrantes que se venían produciendo a raíz de la Revolución Industrial ${ }^{3}$. No obstante, entre las primeras normas laborales destaca ya la Ley de 13 de marzo de 1900 reguladora de las condiciones de trabajo de las mujeres y de los niños, en la que se recogen dos instituciones pioneras: el cese en el trabajo por maternidad con derecho a reserva de puesto durante las tres semanas siguientes al alumbramiento y la concesión de un permiso retribuido de una hora diaria para la lactancia del recién nacido. Es indudable el valor que poseen estas previsiones tempranas en cuanto establecen los fundamentos de una tutela que servirá de punto de partida para la regulación posterior y manifiestan el carácter prioritario que, para el legislador, revisten estas cuestiones frente a otras igualmente acuciantes en ese período como la limitación de jornada o el salario digno. Con todo, un análisis más detenido revela las importantes limitaciones que, desde un principio, acompañaron a esta norma y que determinarán la escasa eficacia real que, finalmente, desplegaría.

a) En lo referente al ámbito subjetivo de la ley, el colectivo al que se dirige es mucho más restringido de lo que a primera vista pudiera parecer. Debe tenerse en cuenta, así, que el trabajo femenino constituye, a comienzos de

3 Vid. en detalle, J. Montalvo Correa, (1975), pp. 148 y ss.; M. J. López Álvarez, (2000); P. NúñezCortés Contreras, (2002b.). 
siglo, una situación casi excepcional, que se justifica exclusivamente por razones económicas ${ }^{4}$. Si a ello se añade el hecho de que dos de las ocupaciones femeninas tradicionales- el trabajo en el campo y el servicio domésticoquedaron fuera de la órbita de aplicación de la norma, el resultado es que las mujeres potencialmente beneficiadas con las ventajas legales se reduce a aquellas que prestaban servicios en la industria, lo que sugiere una escasa repercusión, en términos cuantitativos, de estas previsiones ${ }^{5}$.

b) Por otra parte, y de mayor interés a los efectos que tratamos, es el bien jurídico tutelado por la norma. La imposición de un descanso obligatorio para la trabajadora tras el parto y la concesión de un permiso para atender la lactancia del hijo durante los primeros meses obedece primordialmente a razones de política higiénico-sanitaria, a la necesidad de procurar un descanso mínimo a la trabajadora para su recuperación física y la alimentación del hijo que evitara las consecuencias negativas que "para el porvenir de la raza"-al decir de los autores de la época ${ }^{6}$ podrían derivarse de continuar las condiciones de penuria y miseria en que subsistían los obreros. No se aprecia, pues, un deseo más genérico de protección de la institución familiar ni parece que la intención de la norma sea favorecer la permanencia en el empleo de unas trabajadoras que, en el contexto social e ideológico del momento, acceden al mismo como último recurso para hacer frente a la estrechez económica y, aún así, lo hacen con salarios considerablemente más reducidos que los reconocidos a los obreros varones.

c) La articulación práctica de las previsiones de la ley viene a confirmar la impresión de que nos encontramos ante una declaración bienintenciona-

4 El número de trabajadoras asalariadas existente en España en 1900 era aproximadamente de 1.382 .600 , lo que representa el $18 \%$ de la población activa de la época y únicamente el $14,5 \%$ de las mujeres en edad de trabajar, vid. R. Capel Martínez, (1999), p. 31.

5 Vid. en extenso, P. Núñez-Cortés Contreras, (2002 a).

6 Vid. el informe “El trabajo de la mujer en la industria” presentado por J. GonZÁLEZ CASTRo, ante el Instituto de Reformas Sociales en 1914 en el que se refleja esta preocupación: “No es menester gran esfuerzo para comprender que la situación actual de la obrera ha de provocar funesta influencia en el porvenir de la raza, pues ... ( ) ... basta el agotamiento físico y moral y la miseria en que vive, para que los hijos que procree sean forzosamente seres anormales...".

En esta misma línea, la Exposición de Motivos del Real Decreto Ley de 22 de marzo de 1929 que constituye el Seguro Obligatorio de Maternidad establece entre los principales fines del mismo "... velar por la salud de la madre obrera y de sus hijos y, por consiguiente, aumentar el valor biológico de la raza". 
da pero carente de contenido efectivo. En este sentido, como se puso de manifiesto desde la publicación de la norma ${ }^{7}$, resulta por completo inconsecuente exigir el alejamiento temporal de la trabajadora de su puesto sin prever, simultáneamente, ningún tipo de subsidio o ayuda que compense durante este período la pérdida de salario. De hecho, la imposibilidad de soportar una disminución de ingresos tan prolongada fue el motivo principal de la inobservancia de las prescripciones legales por parte de las propias trabajadoras afectadas. Pasarán, no obstante, varios años antes de que se conciba el Seguro Obligatorio de Maternidad en 1923 destinado a cubrir esta contingencia y transcurrirán todavía algunos más antes de que se ponga en funcionamiento ${ }^{8}$. Ello refleja, ya desde este momento, lo que constituirá uno de los problemas más controvertidos y que más frecuentemente han supuesto un freno para estas iniciativas, como es el del sujeto que deba responsabilizarse del coste de las mismas, sobre todo cuando éste es de contenido económico. Deesta forma, uno de los principales focos de incumplimiento de la norma proviene de los empresarios y sus comprensibles reticencias a aceptar intromisiones que limitan sus facultades organizativas y generan cargas adicionales. A lo cual se sumará, en este caso concreto, el rechazo de las trabajadoras que, o bien carecen de medios suficientes que aseguren su sustento durante el período de descanso, o bien temen la reacción negativa del empresario si tratan de hacer valer su derecho. Y es éste otro de los aspectos que se anuncia como una constante en las regulaciones que aparecerán con posterioridad, ya que en muchas ocasiones, la aparición de normas en apariencia neutras que favorecen la conciliación de la vida familiar y profesional terminan produciendo un efecto negativo en el empleo de los destinatarios, fundamentalmente muje-

7 Desde diversos sectores, pero especialmente desde los círculos obreros, se denunció esta grave deficiencia de la ley que, de hecho, constituyó uno de los puntos principales en los que se basó la contestación obrera a la misma. Vid., así, la posición de los representantes obreros del Instituto de Reformas Sociales que señalan que “... poco importa, en efecto, que la mujer descanse, si la supresión del trabajo le priva de cosas tan absolutamente necesarias y la deja en una situación de abandono incompatible con todos esos cuidados, y haciendo que su ausencia legal en el taller sea todo lo contrario a una ventaja..." , cit. en A. MARVAUD, (1975), p. 251.

8 De hecho, el RD 21 agosto de 1923 que regula por vez primera este Seguro de Maternidad, establece para su financiación un régimen de subsidios provisional a cargo del Estado en tanto no se creara la Caja del Seguro de Maternidad. No obstante, ésta no se recoge como tal hasta el RD 29 enero de 1930 y no entrará en funcionamiento hasta el 1 de octubre de 1931, dentro ya, por tanto, del período republicano.

9 En relación con esta cuestión, J. González CASTRo, (1914), p. 13 señala cómo la hora de lactancia 
res, al provocar la retracción de los empresarios a su contratación ${ }^{9}$.

d) Pesea todas las dificultades apuntadas, la ley de 1900 no sólo mantendrá su vigencia, con escasas modificaciones, durante varias décadas, sino que el modelo de regulación que establece para el descanso por maternidad pervivirá prácticamente intacto hasta fechas muy recientes. Como señala al gún autor ${ }^{10}$, esta circunstancia obedece probablemente a factores sociales e ideológicos antes que al grado de perfección técnico-jurídico de la norma que, como hemos visto, resulta muy discutible. Y es que, en definitiva, con la implantación del régimen franquista se concederá carta de naturaleza a unas estructuras sociales en las que, como refleja la ley de 1900, las cargas familiares son competencia exclusiva de la mujer y, en consecuencia, el acceso de ésta al ámbito laboral constituye un supuesto aislado y excepcional o, cuando menos, no deseable. Unicamente durante el breve paréntesis que supone en este sentido la II República pueden encontrarse algunas previsiones que, contraviniendo esta tendencia, tratan de garantizar la permanencia en el empleo de la mujer con responsabilidades familiares ${ }^{11}$, pero es evidente que su escasa duración y el marco político en el que se inscriben condicionará la eficacia casi simbólica que cabe atribuir a las mismas.

\subsection{El régimen franquista}

La particular idiosincrasia del régimen franquista marca una segunda etapa en la que la exaltación política de los valores familiares tendrá una influencia decisiva sobre la materia que estudiamos. La opción ideológica por un modelo conservador de familia que atribuye a la mujer el papel de esposa y madre, dedicada por completo a las tareas del hogar y de la crianza de los hijos, llevará a su apartamiento sistemático del mercado de trabajo12.

que contempla la Ley de 1900 no se observa en la mayoría de las fábricas, por el simple hecho de que el patrono procura no emplear a obreras que se hallen en tales circunstancias.

10 M. C. Palomeque López, (1975-76), p. 270.

11 Así destaca, por ejemplo, el art. 9 de la Ley de contrato de trabajo de 21 de noviembre de 1931 que considera injustificado el despido que se basa en la ausencia de la trabajadora durante el descanso por maternidad; o bien el Decreto de 9 de diciembre de 1931 que declara la nulidad de las cláusulas contractuales que recogen como causa de extinción del contrato de trabajo el matrimonio de la obrera.

12 Es de sobra conocida, en este sentido, la Declaración II.1 del Fuero del Trabajo, en la que se 
De esta forma, los problemas para la conciliación de la esfera profesional y familiar se minimizan en cuanto se abordan no ya desde la perspectiva de dos realidades que friccionan, sino desde la separación radical de ambas en función del sexo, concediendo al hombre y a la mujer un protagonismo definido en cada una de ellas. Ha de hacerse notar, en todo caso, que estos planteamientos iniciales se irán suavizando con el paso del tiempo y con la progresiva liberalización del régimen coincidiendo con la expansión económica de los años 60. Pero es igualmente cierto que el sustrato ideológico sobre el que se asientan permanece, en esencia, inalterado, impidiendo una aceptación real de la presencia de la mujer en la vida profesional y retrasando considerablemente la búsqueda de fórmulas dirigidas al trabajador con responsabilidades familiares.

a) Durante los primeros años del franquismo, pues, como se ha señalado, la defensa a ultranza de la institución familiar cristalizará en disposiciones de corte restrictivo, que imponen limitaciones a la mujer para el acceso o la permanencia, a partir de un determinado momento, en el ámbito laboral. De entre ellas ${ }^{13}$, probablemente la más conocida y con mayor repercusión es una institución peculiar, la excedencia por matrimonio.

La excedencia forzosa por matrimonio se recoge en numerosas Reglamentaciones u Ordenanzas de Trabajo, normas reglamentarias que determinan, como se sabe, durante este perío do las condiciones de trabajo en cada sector de actividad. En virtud de la misma, la mujer pasa automáticamente a la situación de excedencia forzosa al cambiar de estado civil, percibiendo en ocasiones por este motivo, una compensación económica de cuantía variable, la denominada "dote" por matrimonio. Analizando las condiciones que las Ordenanzas imponían para permitir el reingreso de la mujer- que ésta se convirtiera en cabeza de familia o el marido quedara imposibilitado para el trabajo- puede concluirse que lo que en un principio constituía una simple excedencia encubría, en realidad, un auténtico despido, de forma que, en

pretende liberar a la mujer casada del "taller y de la fábrica", lo que se interpretaría, en su momento, como una exhortación a restringir la actividad profesional de la mujer en general $y$, en especial, de aquélla con cargas familiares.

13 En este sentido, pueden citarse numerosas previsiones que, directa o indirectamente, tratan de apartar a la mujer del trabajo asalariado. Así, por ejemplo, la prohibición de trabajo nocturno que aparece en el Fuero del Trabajo o las Ordenes de 27 de diciembre de 1938 y 17 noviembre 1939 que niegan a la mujer casada la posibilidad de encontrar empleo a través del Servicio Público de Colocación. 
muchos casos, la única vía para que la mujer conservara su empleo sería permanecer soltera ${ }^{14}$. Con este mecanismo quedaba asegurada la dedicación de la mujer a los deberes familiares y, correlativamente, su alejamiento definitivo, salvo supuestos excepcionales, del ámbito profesional.

b) A partir de cierto momento, sin embargo, el régimen comienza a mostrar sus primeros signos de apertura y, entre ellos, se producen tímidos atisbos que tratan de romper la discriminación social que la mujer viene padeciendo, proclamando formalmente su equiparación con el hombre. Aparece, así, la Ley de 22 de julio de 1961 sobre Derechos Políticos, Profesionales y de Trabajo de la Mujer que prohíbe cualquier discriminación por razón de sexo o estado civil en el ámbito laboral ${ }^{15}$. Deben entenderse, por tanto, derogadas a raíz de la misma todas las previsiones contenidas en las Ordenanzas y Reglamentaciones acerca de la exced encia forzosa por matrimonio, pese a lo cual se admitirá entonces la posibilidad de que la trabajadora opte libremente en caso de matrimonio por alguna de las tres siguientes alternativas: a) continuar su prestación de servicios en idénticas condiciones, b) rescindir su contrato de trabajo percibiendo una indemnización, c) quedar en situación de excedencia voluntaria por un período mínimo de un año y máximo de tres.

Como puede comprobarse, la Ley de 1961 marca un punto de inflexión en cuanto a la desaparición de normas que proscriben abiertamentela actividad profesional de la mujer. No obstante, la concepción tradicional que vincula a la mujer con responsabilidades familiares al entorno doméstico seguirá estando presente en las iniciativas del legislador y, si bien se abandona la vía coercitiva, se tratará de desincentivar el trabajo femenino a través de otro tipo de medidas. En un plano negativo, resulta significativa la regulación que del descanso por maternidad se contiene en la Ley de Contrato de Trabajo de $1944^{16}$ que, como ya se indicó, reproduce casi literalmente el esquema protector que se configura en la Ley de 1900 y apenas experimentará variaciones a lo largo de los años, poniendo de manifiesto el desinterés del legislador por ampliar la tutela que merecen estos supuestos u ofrecer alternativas que favorezcan la permanencia de la mujer en el ámbito laboral

14 De "celibato contractual" califican esta situación G. Bayón Chacón-E. Pérez Botija, (1961), p. 316.

15 Vid. en extenso, M. Alonso Olea, (1961), p. 327 y ss.

16 Arts. 166-167.

\section{RFS}


tras la maternidad. Y, desde otra perspectiva, las disposiciones que aparecen en esta última etapa aportan escasas novedades a la línea iniciada con la Ley de 1961. En este sentido, por ejemplo, el Decreto de 20 agosto 1970 sobre Derechos laborales de la mujer esboza algunas figuras de interés como la excedencia por cuidado de hijo o la reducción de jornada pero sin llegar a articular, no obstante, los mecanismos necesarios para que su aplicación resulte eficaz ${ }^{17}$. Mientras que, por otro lado, se recoge de forma expresa la triple opción para la trabajadora que contrae matrimonio, consolidando con ello una presión implícita sobre la mujer para que abandone su puesto de trabajo con el señuelo económico de la dote ${ }^{18} 0$, al menos, solicite una excedencia voluntaria que generará numerosos problemas para el reingreso y que, todavía hoy, continúa siendo fuente de conflictos por ese motivo ${ }^{19}$.

17 El trabajo en régimen de jornada reducida o media jornada se contempla, así, como un simple derecho de preferencia de las mujeres que buscan empleo a través del Servicio Nacional de Colocación. Y, en lo que respecta a la excedencia para cuidado de hijo, no se regula un derecho a reserva del puesto de trabajo, por lo que la reincorporación queda condicionada a la existencia de vacante dentro de la categoría profesional.

18 Con el agravante de que, como señala I. AlBiol Montesinos, (1981), p. 59 se obliga al empresario al pago de una indemnización por un hecho, el matrimonio, que no guarda vinculación alguna con el contrato de trabajo.

19 Con la promulgación de la Constitución de 1978, los preceptos legales y de las Reglamentaciones relativos a la excedencia por matrimonio quedan derogados y sin efecto por su colisión con el principio de igualdad. El Tribunal Constitucional (SS 14, 18 y 23 febrero de 1983, entre otras) fijará, no obstante, en diversos pronunciamientos un plazo general de prescripción de tres años (tomando como referencia el art. 83 Ley de Contrato de Trabajo entonces vigente) para la solicitud de reingreso a partir de la aparición del texto constitucional lo que, si bien es cierto que ha frenado la reincorporación de muchas trabajadoras excedentes, no ha conseguido zanjar por completo esta cuestión. Dos sentencias recientes confirman esta impresión: la primera, Sentencia del Tribunal Superior de Justicia (en adelante, STSJ ) de Madrid 8 octubre 2002, reconoce el derecho de reingreso de una empleada de banca excedente desde 1974 en aplicación de la cláusula del Convenio Colectivo de Banca de 1996 que declara en vigor el contenido de la Ordenanza en la que aparecía la regulación de la excedencia por matrimonio lo que, a juicio del Tribunal, supone una renuncia a la prescripción ganada en 1981, restableciendo ex novo el derecho a la reincorporación tras la muerte del marido. En parecidos términos, la STSJ Andalucía 17 octubre 2002 confirma la imposibilidad de alegar prescripción en el ejercicio del derecho al reingreso cuando el mismo se contempla en el convenio colectivo de aplicación. 


\subsection{Etapa constitucional}

a) El período preconstituyente: la Ley de Relaciones Laborales

La implantación del sistema democrático configura, finalmente, un nuevo marco para el desenvolvimiento de las relaciones laborales con importantes implicaciones para las cuestiones que analizamos. La consagración en nuestra Carta Magna del principio de igualdad y la prohibición de discriminación por razón de sexo constituye, sin duda, a estos efectos un elemento clave para respaldar las aspiraciones laborales de la mujer y obliga, en suma, a situar las medidas de conciliación de la vida familiar y profesional en un contexto diferente. No obstante, y pese a todo, las transformaciones que se producen en este períod o tienen, probablemente, menor calado del que en inicio pudiera parecer. En muchos aspectos, como ocurre con el trabajo extradoméstico de la mujer, la labor del legislador se limita a refrendar una realidad socialmente extendida pero sin el eco normativo adecuado debido a la rígida concepción de la institución familiar de la que había venido haciendo gala el régimen precedente. Y en otros, en cambio, se echa en falta una política con mayor amplitud de miras que, venciendo inercias sociales, atienda a las necesidades reales que surgen a largo plazo como consecuencia de esa incorporación de la mujer a la vida profesional activa o de la aparición de nuevos modelos de familia; lo que se traduce, en definitiva, en la búsqueda de alternativas imaginativas que permitan la atención a los intereses familiares sin sacrificar necesariamente, como había ocurrido hasta el momento, la estabilidad profesional de alguno de los miembros de la comunidad familiar.

Una primera muestra de este cambio de orientación se encuentra en la Ley de Relaciones Laborales (en adelante, LRL) que se aprueba en 1976 en la antesala de la transición democrática. Como ha señalado algún autor ${ }^{20}$, se trata de una norma particularmente significativa por cuanto, teniendo en cuenta el momento histórico en el que aparece, sus previsiones resultan de las más progresistas de los países de nuestro entorno y anticipan, en muchas materias, las líneas por las que se va a avanzar en la etapa que comienza. Entre las propuestas que incorpora la LRL para favorecer las responsabilidades familiares del trabajador se aprecia también esta especial sensibilidad del legislador, que introduce modificaciones importantes en el régimen jurídico

20 C. Molero Manglano, (1999), p. 130.

\section{RFS}


de instituciones ya existentes como la hora de lactancia, fijando un plazo máximo para su disfrute y desvinculándola de la lactancia natural del hijo, lo que abrirá el paso para el ejercicio del derecho en el futuro por el padre; e, igualmente, regula por vez primera la posibilidad de solicitar una reducción de jornada para el cuidado de un menor de seis años, reconociendo con ello la necesidad de ampliar una tutela demasiado restringida y circunscrita al momento puntual del nacimiento del hijo.

\section{b) La Constitución de 1978 y la evolución normativa posterior}

Otro hito decisivo, como ya adelantábamos, es el reconocimiento del principio de igualdad en el art. 14 de la Constitución, que pone fin a las barreras formales que habían venido dificultando el acceso de la mujer al mercado laboral y, especialmente, su permanencia en el mismo tras la maternidad. La contundencia con la que se proclama la igualdad de sexos en el texto constitucional se refuerza con la interdicción de cualquier discriminación por este motivo y parece, por tanto, que más allá de una mera uniformidad o paridad formal, se trata de obtener una igualdad efectiva y real entre hombres y mujeres; una identidad sustancial que implique, en suma, una igualdad de oportunidades y elimine la situación de marginación e inferioridad en que, históricamente, se ha encontrado la mujer ${ }^{21}$. En aplicación de estos criterios, las normas laborales abordan a partir de este momento el problema de las cargas familiares del trabajador bajo un doble prisma: procurar, en primer término, un reparto más equilibrado de las obligaciones familiares favoreciendo una implicación mayor del trabajador varón en las mismas; y articular, por otra parte, las medidas precisas para que el trabajador pueda, con independencia de su sexo, compaginar con cierta soltura sus responsabilidades en el ámbito profesional y privado 22 . Un exponente claro de ello es la Ley 3/89 que, con la finalidad de asegurar la

21 Cfr. M. Rodríguez-Piñero, (1993), p. 20, Mạ F. Fernández López, (1993), p. 154 para quien "Ia positivización de la prohibición de discriminación parte de la constatación de la existencia en la sociedad de grupos o colectivos de personas sistemáticamente marginados, ciudadanos con una posición secundaria respecto de aquellos que gozan o pueden gozar de plenitud de posiciones de ventaja, pese al formal reconocimiento de su condición de 'iguales' a éstos".

22 Se pasa, como señala T. Sala Franco, (1992), p. 7, de una protección jurídica subjetiva de la mujer con responsabilidades familiares a una protección objetiva de las responsabilidades familiares, independientemente de quién las asuma (hombre o mujer). 
igualdad de trato de la mujer en el trabajo ${ }^{23}$, amplía al padre el disfrute de algunos derechos vinculados tradicionalmente a la trabajadora en exclusiva, como es la licencia por maternidad ${ }^{24}$ o el permiso por lactancia. $Y$, junto con ello, introduce mejoras significativas en otras figuras que atienden a las cargas familiares del trabajador, racionalizando el ejercicio de las mismas y fijando, por ejemplo, el derecho a reserva de puesto de trabajo durante el primer año de excedencia por cuidado de hijo ${ }^{25}$ o la suspensión del contrato por maternidad en supuestos de adopción ${ }^{26}$.

En todo caso, la búsqueda de una equiparación material entre hombres y mujeres reviste una complejidad que excede cualquier planteamiento meramente formalista y revela la imposibilidad de alcanzar, a corto plazo, soluciones plenamente satisfactorias. Resulta ilustrativa la posición del Tribunal Constitucional que, tras una etapa inicial de reconocimiento genérico de la igualdad circunscrita a una valoración de las diferencias irrazonables de trato 27 , admite en un segundo momento la insuficiencia de estos juicios neutros de igualdad y entra a considerar la problemática de la discriminación entre sexos desde la perspectiva de una situación en origen de marginación de la mujer. Partiendo de esta premisa, se justificará una tutela más cualificada de la mujer trabajadora que comprenda la adopción de medidas de acción positiva tendentes a superar las diferencias que, de antemano, limitan la posición de la mujer en el entorno laboral, y así se admite, por ejemplo, la

23 Resulta significativo a estos efectos que el Ministro de Trabajo, en su comparecencia ante el Senado para la presentación de la Ley, fijara como objetivo principal de la misma el "articular los mecanismos de garantía necesarios para facilitar la permanencia de la mujer en el trabajo", vid. A. Sempere Navarro, (1989), p. 86.

24 En concreto, se permite que la trabajadora ceda al padre hasta cuatro de las dieciséis semanas de suspensión a que tiene derecho por nacimiento de hijo.

25 Como indica la exposición de Motivos de la Ley la configuración de esta figura como una excedencia voluntaria sin derecho a reserva de puesto, "podía constituir bien un serio factor de disuasión para el pase a esta situación, bien un elemento de apartamiento del mercado de trabajo de quienes se acogiesen a esta fórmula".

26 Vid. R. Escudero Rodríguez, (1989) y también T. Velasco Portero, (2002).

27 Vid. la Sentencia del Tribunal Constitucional (en adelante, STC) 22/1981, de 2 julio, donde se plasma perfectamente esta doctrina: "La igualdad es sólo violada si la desigualdad no está provista de una justificación objetiva y razonable, y la existencia de dicha justificación debe apreciarse en relación a la finalidad y efectos de la medida considerada, debiendo darse una relación razonable de proporcionalidad entre los medios empleados y la finalidad perseguida". 
concesión de un plus de guardería que se reconoce por convenio únicamente para las trabajadoras ${ }^{28}$ o la titularidad en exclusiva para éstas (antes de la reforma introducida por la Ley $3 / 89$ ) del permiso por lactancia ${ }^{29}$. Desde esta perspectiva, pues, las desigualdades de trato que favorecen a la mujer en el ámbito laboral no sólo dejan de sancionarse sino que se aprueban abiertamente cuando tengan como finalidad la obtención de una igualdad real que le ha sido vedada a este colectivo tradicionalmente, y siempre que tales diferencias no constituyan un reflejo más de dicha marginación que contribuya a perpetuarla, como ocurría con las disposiciones que limitaban el trabajo nocturno femenino.

En fechas más recientes, sin embargo, se percibe una revisión crítica de esta línea que pone en cuestión la eficacia real que esta tutela antidiscriminatoria puede desplegar en la situación laboral de la mujer. Se hace hincapié, así, en los efectos negativos que pueden derivarse de una política de "sobreprotección" de la mujer ya que, como indicara en su momento el voto particular de la Sentencia 109/93 del Tribunal Constitucional (en adelante, STC), "a nadie se le oculta que, para un empresario poco escrupuloso con el principio de igualdad, siempre le será más rentable contratar a hombres que a mujeres trabajadoras, dado el incremento de los costes laborales que, por estas causas y otras biológicas, las mujeres siempre ocasionan". Ello ha llevado a defender el embarazo como único factor diferencial por razón de sexo admisible en el entorno empresarial al tratarse de un proceso biológico que afecta a la mujer en exclusiva ${ }^{30}$, pero sin que resulte justificada una

28 STC 128/1987, 16 julio en cuyo fundamento jurídico 10 으 se señala que "a efectos laborales la diferencia entre hombres y mujeres con hijos de corta edad no es únicamente de sexo y reside en que existe una innegable y mayor dificultad para la mujer con hijos de corta edad para incorporarse al trabajo o permanecer en él, y en tanto esa realidad perdure, no pueden considerarse discriminatorias las medidas tendentes a favorecer el acceso al trabajo de un grupo en situación de clara desigualdad social".

29 STC 109/1993, 25 marzo. En el voto particular de la sentencia, no obstante, se cuestiona la solución alcanzada por el Tribunal argumentando que la concesión de derechos suplementarios a la mujer puede convertirse, a la larga, en un factor material de discriminación para ésta, alejándola del mercado de trabajo. Se anticipa, así, la línea de reflexión que aparecerá en decisiones posteriores y que llevará, igualmente, a la modificación legal del permiso por lactancia del art. 37.4 Estatuto de los Trabajadores para ampliar su disfrute al padre.

30 STC 173/94, 240/99. En la misma dirección se mueve la jurisprudencia comunitaria sobre la materia, Sentencia del Tribunal de J usticia de la Comunidad Europea (en adelante, ST J CE 25 de julio de 1991 (caso Stoeckel), 30 de abril de 1998 (caso Thibault) entre otras, vid. al respecto, J. CRUZ VILLALón, (1997). 
interpretación extensiva del mismo y de la maternidad, que termine por atribuir a la mujer unas responsabilidades que no le corresponden necesariamente $^{31}$. No obstante, yendo más allá, viene a constatarse que incluso aquellas disposiciones en apariencia neutras que regulan las responsabilidades familiares del trabajador pueden llegar a actuar como un elemento más de discriminación indirecta, al ser las mujeres las que principalmente van a hacer uso de tales facilidades. De esta forma, medidas destinadas en principio a favorecer las cargas familiares de cualquier trabajador, como la excedencia por cuidado de hijo o la reducción de jornada, terminan originando consecuencias no deseadas sobre el empleo femenino y contribuyen a consolidar el rol tradicional de la mujer en el ámbito doméstico ${ }^{32}$.

En definitiva, y a modo de balance, la experiencia de las dos últimas décadas indica que se han producido cambios de gran calado en el tratamiento legislativo y jurisprudencial de los problemas que suscita para el trabajador la conciliación de la vida familiar y profesional, coincidiendo con la incorporación masiva de la mujer al ámbito laboral y el nuevo escenario que se conforma a partir de ello. Quedan, no obstante, rémoras importantes en el entorno social, que sigue ejerciendo una considerable presión sobre la mujer para que asuma las tareas familiares, incluso cuando éstas se manifiestan abiertamente incompatibles con el ejercicio de una actividad profesional. Por ello, la actuación de los poderes públicos debe ser en este punto extremadamente cautelosa ya que, sin renunciar a la consecución de una igualdad sustantiva entre hombres y mujeres, ha de valorar con perspectiva crítica la finalidad y el alcance práctico de los instrumentos que pone a disposición de los trabajadores para asegurar y facilitar a éstos el cumplimiento de sus obligaciones familiares, sin que ello implique un deterioro de su estabilidad profesional.

\section{c) La Ley de conciliación de la vida familiar y laboral: valoración crítica}

En el contexto que se ha descrito, las iniciativas más recientes del legislador se aglutinan en torno a la Ley 39/99 de conciliación de la vida

31 Maj. Nevado Fernández, (2000), p. 372 critica, por ejemplo, aquellas opiniones que condicionan el bienestar del hijo durante los primeros meses de vida a los cuidados recibidos de la madre.

32 Entre otras cosas porque, como señala J. CRuz VilLaLón, (1999), p. 74, las retribuciones de hombres y mujeres están todavía lejos de equipararse y el salario de la mujer sigue siendo, a estos efectos, un complemento al del varón que constituye el principal sostén de la familia.

\section{RFS}


familiar y laboral de las personas trabajadoras. Como ya ocurriera con la Ley $3 / 89$, la publicación de la Ley de Conciliación ha venido precedida de una expectación que puede contrastar, a priori, con la escasa originalidad de su contenido. Nos encontramos, así, ante una norma continuista que no modifica sustancialmente el marco jurídico preexistente, entre otras razones, porque al tratase de una ley laboral su campo de actuación resulta claramente insuficiente para abordar estas cuestiones desde su globalidad $^{33}$. No obstante, bajo nuestro punto de vista, la Ley de Conciliación de 1999 reviste interés en cuanto persevera en la línea iniciada con la norma de 1989, tanto en el enfoque con que se regulan las responsabilidades familiares del trabajador como en los bienes y sujetos que se trata de proteger. Atendiendo a los requerimientos reiterados que había venido realizando la doctrina, se amplía el concepto de cargas familiares, hasta entonces circunscrito a los hijos y en algunos casos el cónyuge, para contemplar igualmente a los familiares cercanos que, por edad o enfermedad, pueden precisar una dedicación más intensa. Las obligaciones familiares del trabajador entran, por esta vía, en un proceso de racionalización y adquieren tintes de normalidad frente al carácter extraordinario y puntual que habitualmente ha acompañado su regulación. $Y$, por otra parte, se trasluce de forma cada vez más intensa la preocupación del legislador por salvaguardar la estabilidad en el empleo del trabajad or que asume responsabilidad es de esta naturaleza, bien arbitrando mecanismos específicos de tutela (la presunción de nulidad del despido a la que luego se hará referencia), bien introduciendo nuevas fórmulas que permitan, sobre todo en el caso de la mujer, compatibilizar la esfera familiar y profesional con el menor coste posible y así se amplía a diez semanas el período de disfrute por el padre del permiso por maternidad, se permite el disfrute de la licencia por maternidad a tiempo parcial ${ }^{34} y$, en general, se conceden las máximas facilidades para que el trabajador ejercite los derechos vinculados a la vida familiar como la excedencia o la reducción de jornada.

Indudablemente, la armonización de dos ámbitos con intereses encontrados implica la búsqueda de un equilibrio siempre delicado y difícil de alcanzar. Las recientes intervenciones del legislador merecen, sin embargo, una valoración positiva por cuanto han significado un impulso importante

33 Para una visión crítica, vid. J. Gorelli Hernández, (1999); M. J. López Álvarez- P. Núñez-Cortés Contreras, (2003).

34 Desarrollado por el RD 1251/2001, de 16 noviembre. 
para la consecución del mismo y hacen previsible un incremento de las iniciativas en otros ámbitos- algunas de las cuales se están produciendo ya ${ }^{35}$ que consoliden definitivamente las responsabilidades familiares como un factor más de la relación de trabajo con el que se debe contar, con independencia, además, de cuál sea el sexo del trabajador.

\section{Medidas específicas de protección frente a la ruptura injustificada del contrato de trabajo contempladas en la Ley de la conciliación de la vida laboral y familiar}

De entre las medidas encaminadas a potenciar el equilibrio entre la vida profesional y familiar contenidas en la Ley 39/99, interesa sobre todo al objeto de nuestro estudio, el análisis de aquellas que de manera específica se dirigen a reforzar el bien jurídico de la estabilidad en el empleo de los trabajadores. Como ya se ha puesto de manifiesto a lo largo de este trabajo, la maternidad y el ejercicio de los derechos que ampara el ordenamiento por razones familiares son posiblemente algunas de las situaciones que resultan más delicadas para dicha estabilidad en el empleo. El análisis de la jurisprudencia de suplicación de los últimos diez años anteriores a la promulgación de la Ley 39/99 proporciona una casuística que demuestra que en numerosas ocasiones, desde los primeros momentos del embarazo, las alteraciones en la salud de la madre son utilizadas por el empresario para poner en marcha mecanismos encaminados a la resolución de su contrato. Así pues, se producen un significativo número de situaciones en que el empresario aprovecha la ausencia por maternidad de la trabajadora para sustituirla de modo definitivo por otro trabajador u obstaculizar su reincorporación después del descanso; o bien extingue o no prorroga el contrato temporal, o

35 A nivel de empresa, está pendiente una actuación más decidida de la negociación colectiva que permita adecuar las circunstancias específicas del entorno productivo a las necesidades familiares del trabajador (cambios de turnos, horarios flexibles, permisos retribuidos, traslados...). En este sentido, el Instituto de la Mujer en colaboración con el Ministerio de Trabajo desarrolla actualmente el Plan Optima para implantar medidas de acción positiva en las empresas que favorezcan la igualdad entre hombres y mujeres y la conciliación de la vida familiar y profesional, vid. sobre las empresas incluidas en el plan, La gaceta de los negocios, 27 enero 2003.

En otros ámbitos, puede citarse, por ejemplo, la Ley $6 / 2002$ de la Generalidad de Cataluña por la que se reconoce el derecho a la reducción de un tercio de la jornada de trabajo con mantenimiento de la retribución durante el primer año de vida del hijo para los funcionarios de las administraciones públicas catalanas. 
pone fin al mismo durante el período de prueba. La elevada tasa de temporalidad que sufre el colectivo de trabajadoras incide de modo claro en el empeoramiento de la estabilidad en el empleo de la mujer por motivos relacionados con la maternidad ${ }^{36}$.

En este sentido, como ya se ha señalado, la Ley 39/99 constituye, sin duda, el intento más ambicioso llevado a cabo por el legislador de reforzar el bien jurídico de la estabilidad en el empleo de los trabajadores con responsabilidades familiares. La fórmula utilizada por el legislador ha consistido en crear un mecanismo de protección específico para los despidos producidos durante el ejercicio de dichas responsabilidades; se trata de un mecanismo de garantía especializado y diferenciado del que existe con carácter general para los despidos discriminatorios. La eficacia de esta nueva garantía, cuyo alcance analizaremos en el apartado siguiente, presenta una quiebra en origen; solamente ha sido diseñada para los despidos disciplinarios y las extinciones objetivas, dejando fuera supuestos de ruptura del contrato de trabajo, tales como la rescisión durante el período de prueba o la falta de renovación de los contratos temporales; o los despidos colectivos, etc... Estas situaciones de falta de continuidad de la relación laboral no contempladas expresamente por la norma encontrarán una solución, aunque menos eficaz, en la tutela que con carácter general se establece para los despidos discriminatorios; hoy por hoy la jurisprudencia no se ha hecho eco de una interpretación de la norma lo suficientemente extensiva que permita su asimilación a la tutela reforzada establecida para los supuestos de despido disciplinario y objetivo.

3.1. La presunción de nulidad del despido disciplinario y la extinción por causas objetivas

La fórmula de protección adoptada por esta norma es en gran parte el resultado de la transposición a nuestro derecho interno de diversas iniciativas legislativas adoptadas en el ámbito internacional, entre las que cabe destacar, en el marco de la Unión Europea, la Directiva 92/85, de 19 de octubre $^{37}$. Esta última norma incorporaba un mecanismo de garantía consis-

36 R. Escudero Rodríguez, (1994), p. 261.

37 Art. 10 Directiva 92/85: "Prohibición de despido.1) Los estados miembros tomarán las medidas necesarias par prohibir el despido de las trabajadoras a que se refiere el artículo 2 , 
tente en una prohibición del despido de la trabajadora durante el período comprendido entre el inicio del embarazo y el final del permiso por maternidad; excepto cuando se produzca por motivos no relacionados con la maternidad y esté fundado en una causa legítima reconocida por las legislaciones nacionales. Una garantía similar, pero de mayor alcance, incorporaba el nuevo convenio 183 de la Organización Internacional del Trabajo, de 15 de junio del año 2000 , sobre protección a la maternidad, dado que ampliaba el período protegido más allá de la finalización del permiso por maternidad y liberaba a la trabajadora de la carga de la prueba en los despidos producidos en estas circunstancias, haciendo recaer la prueba en exclusiva sobre el empresario ${ }^{38}$. Hasta el año 1999, estos mecanismos de protección descritos procedentes de la normativa internacional, resultaban inéditos en nuestro ordenamiento, que simplemente se limitaba a considerar discriminatorios, y, por tanto, nulos, los despidos que tenían como motivación el estado de maternidad de la trabajadora. Por esta vía, se otorgaba a la trabajadora un nivel de protección inferior al de las normas internacionales, dadas las enormes dificultades probatorias para acreditar el carácter discriminatorio de estos despidos. Finalmente nuestro legislador, a pesar de ser consciente del efecto negativo que tal medida podría tener sobre la contratación de las mujeres, se decantó por reforzar la estabilidad en el empleo de los trabajado-

durante el período comprendido entre el comienzo del embarazo y el final del permiso por maternidad a que se refiere el apartado 1 del artículo 8, salvo en los casos excepcionales no inherentes a su estado admitidos por las legislaciones y o / prácticas nacionales y, en su caso, siempre que la autoridad competente haya dado su acuerdo.

2) cuando se despida a una trabajadora, a que se refiere el artículo 2, durante el período contemplado en el punto 1 , el empresario deberá dar motivos justificados de despido por escrito.

3) Los estados miembros tomarán las medidas necesarias para proteger a las trabajadoras, a que se refiere el artículo 2, contra las consecuencias de un despido que sería ilegal en virtud del punto 1.

Se trata de una norma sobre seguridad e higiene en el trabajo relativa a "la aplicación de medidas para promover la mejora de la seguridad y la salud en el trabajo de la trabajadora embarazada, que haya dado a luz o en período de lactancia".

38 Art. 8 Convenio 183 OIT: “Se prohíbe al empleador que despida a una mujer que esté embarazada durante la licencia mencionada en los artículos 4 y 5 , o después de haberse reintegrado al trabajo durante un período que ha de determinarse en la legislación nacional, excepto por motivos que no estén relacionados con el embarazo, el nacimiento del hijo y sus consecuencias y la lactancia. La carga de la prueba de que los motivos del despido no están relacionados con el embarazo, el nacimiento del hijo y sus consecuencias o la lactancia incumbirá al empleador". 
res con responsabilidades familiares a la vez que dar cumplimiento a las exigencias de la normativa internacional, adoptando una fórmula de protección que, como veremos a continuación, se inspira claramente en dicha normativa internacional y nuestra experiencia legislativa anterior ${ }^{39}$. El Convenio núm. 183 de la OIT se gestó prácticamente a la vez que la Ley 39/99, su influjo, así como el de la Directiva 92/85, resulta patente en la nueva redacción dada por la Ley de la conciliación de la vida familiar y profesional a los artículos sobre la regulación del despido contenidos en el Estatuto de los Trabajadores ${ }^{40}$.

A partir de la Ley 39/99 se actualiza en nuestro ordenamiento un mecanismo de garantía consistente en la presunción de nulidad de los despidos disciplinarios y por causas objetivas producidos durante el período comprendido desde el inicio del embarazo hasta la solicitud de la excedencia por cuidado de hijos; con la clara finalidad de proteger a los trabajadores frente a la ruptura injustificada de su contrato durante su transcurso.

La nueva normativa del 99 incorpora un plus de protección para los trabajadores que ven amenazada la conservación de su puesto de trabajo por circunstancias relacionadas con la maternidad y el ejercicio de las responsabilidades familiares; dicho mecanismo consiste en la presunción de nulidad de los despidos, tanto disciplinarios como objetivos, producidos en tales situaciones. En la normativa anterior a 1999, la calificación para dichos despidos cuando encubrían una causa discriminatoria era igualmente la nulidad, sin embargo la dificultad de alcanzar tal calificación era enorme, ya que los trabajadores tenían que probar al menos la existencia de unos indicios de discriminación que invirtieran la carga de la prueba sobre el

39 Cuyo más claro exponente sería el artículo 55.6 del Estatuto de los Trabajadores (1980): “El despido de un trabajador que tenga suspendido su contrato se considerará nulo si la jurisdicción competente no apreciase su procedencia". Este precepto sancionaba con la nulidad cualquier despido realizado durante la suspensión del contrato, a salvo de que fuera apreciada su procedencia excluyendo la posibilidad de su improcedencia.

40 Art. 55 p. 2 del ET: “... Será nulo también el despido en los siguientes supuestos:

a) El de los trabajadores en los períodos de suspensión del contrato de trabajo por maternidad, riesgo durante el embarazo, adopción o acogimiento...

b) El de las trabajadoras embarazadas, desde la fecha del incio del embarazo hasta el comienzo del período de suspensión a que se refiere la letra a), y la de los trabajadores que hayan solicitado uno de los permisos a que se refieren los apartados 4 y 5 del art. 37 de esta Ley, o están disfrutando de ellos, o han solicitado la excedencia prevista en el apartado 3 del artículo 36 de la misma". 
empresario. A partir de la Ley 39/99, la acreditación por parte de la trabajadora de realizarse el acto de despido durante el período protegido por la norma (embarazo, suspensión del contrato por maternidad, riesgo durante el embarazo, lactancia, etc...) hará presumir su nulidad. De esta manera se configura una nueva categoría de despidos, a los que denominamos "nulos cualificados" por incorporar una garantía reforzada, su presunción de nulidad, frente a los despidos discriminatorios comunes ${ }^{41}$. Ahora bien, esta garantía no significa que durante las situaciones protegidas no pueda producirse ningún despido o extinción objetiva que merezca la calificación de procedente, ya que la presunción de nulidad podrá destruirse si el empresario demuestra que el despido se basa en una causa legítima ajena por completo a la maternidad o el ejercicio de las responsabilidades familiares. Por tanto, en la actualidad, la necesidad de la prueba indiciaria queda reservada a los despidos "nulos comunes" o discriminatorios, bastando en los denominados despidos "nulos cualificados" acreditar por parte del trabajador encontrase en una de las situaciones protegidas (embarazo, suspensión del contrato por maternidad, riesgo durante el embarazo, etc...) para presumir su nulidad sin necesidad de prueba alguna que recaerá enteramente sobre el empresario ${ }^{42}$. No obstante, la demostración por parte del empresario de la existencia de una causa, la razonabilidad y proporcionalidad de su decisión determinarán su procedencia. Por consiguiente, la regulación actual sólo admite dos calificaciones posibles para estos despidos cualificados: nulidad o procedencia, eliminándose la improcedencia, que podría conducir a una extinción indemnizada, tanto para el empresario como para el trabajador. Así pues, declarada en tales circunstancias su nulidad, ello significa lógicamente su plena ineficacia y el mantenimiento de la relación laboral con la necesaria reincorporación del trabajador a su puesto de trabajo. Por el contrario, en las demandas por despidos discriminatorios comunes, tal y como sucedía en la regulación anterior, puede eludirse la declaración de nulidad aunque no haya procedencia siempre que la causa no sea discriminatoria pero insuficiente para provocar el despido procedente ${ }^{43}$.

Resumidamente, podemos señalar que la protección otorgada por la normativa actual se configura como un verdadero "blindaje" del contrato

\footnotetext{
41 J. Gorelli Hernández, (1999), p. 45

42 J. Gorelli Hernández, (1999), p. 46.

43 J. Gorelli Hernández, (1999), p. 46.
} 
durante el transcurso de las situaciones protegidas. De modo que, salvo en situaciones de claro incumplimiento, el empresario desistirá del planteamiento del despido ante la imposibilidad de demostrar su procedencia y la amenaza de que sea declarado nulo.

Por consiguiente, la reforma introducida por la Ley 39/99 establece la protección especializada y más adecuada a la situación de los trabajadores con responsabilidades familiares que ha existido hasta el momento en el ordenamiento laboral. La efectividad de esta tutela especializada se obtiene actuando sobre dos circunstancias del régimen del despido, estrechamente relacionadas entre sí: mediante la exclusión de la calificación de improcedencia, por lo que el despido solo podrá ser nulo o procedente y, por lo tanto, la consecuencia del mismo solo podrá ser la readmisión o la finalización de la relación laboral; e incidiendo en la actuación procesal y, en concreto, en la configuración de la actividad probato ria mediante la supresión de la carga de la prueba indiciaria sobre el demandante ${ }^{44}$.

A las reflexiones hasta aquí realizadas y para el caso particular de la extinción del contrato por amortización individual de puesto de trabajo, añadiremos algunos criterios específicos sobre el alcance con que operará la garantía descrita en estos casos. Así pues, a pesar de que no exista por mandato legal otra preferencia en la permanencia que la de los representantes de los trabajadores, el hecho de encontrarse los posibles afectados por la amortización en alguna de las situaciones familiares protegidas, determinará, su prioridad de permanencia; cuando existan uno o varios puestos de trabajo a amortizar de características similares y, por tanto, intercambiables. Esta preferencia se apoya en el respeto a los criterios doctrinales y jurisprudenciales de razonabilidad y ausencia de discriminación a los que tendrá que acomodarse la decisión del empresario en tales circunstancias ${ }^{45}$. En consonancia con dichos criterios, resultará discriminatoria la elección de uno de estos trabajadores que se encuentran ejercitando sus responsabilidades

44 B. Cardona Rubert, (2001), p. 3.

45 F. Durán López, (1987), p. 59; J. A. Monereo Pérez, y A. Fernández Avilés, (1997), p. 236; F. Navarro Nieto, (1996), pp. 232 y ss. En este sentido indica la STSJ de Cantabria de 16 de marzo de 1992 que, a pesar de la inexistencia de normas al respecto, la selección de trabajadores habrá de reunir requisitos de razonabilidad y no discriminación. Añadiendo la STSJ de Baleares de 11 de mayo de 1995 que en "en cualquier caso la designación no puede ser caprichosa o arbitraria, debe ser coherente con los fines buscados y responder al principio de que la amortización de los puestos de trabajo se materialice del modo en que ocasione el menor sacrificio de los intereses ajenos posible". 
familiares, bien en solitario o junto a otros, cuando el resto de los de su categoría o grupo profesional con polivalencia de funciones permanezcan en la empresa ${ }^{46}$. No obstante, ante la ausencia de trabajadores de las mismas características para aplicar la prioridad, la medida extintiva podría también afectar a estos trabajadores como sucede en ese caso con los representantes del personal ${ }^{47}$. El ámbito operativo funcional de esta garantía, de grado inferior a la de los representantes de los trabajadores, será el de la empresa, más allá del centro de trabajo, el departamento o la sección, y, por tanto, existiría aunque se produjera el cierre de su centro de trabajo.

3.2. La ausencia de protección especifica para los contratos temporales en la Ley de la conciliación de la vida familiar y laboral

Es innegable que la garantía descrita supone un refuerzo de la estabilidad en el empleo de estos trabajadores respecto a la regulación anterior; sin embargo, como ya hemos mencionado a lo largo de este trabajo, al estar exclusivamente prevista para los despidos disciplinarios y objetivos, deja fuera otros supuestos de rescisión del contrato, entre los que cabe destacar, por su incidencia en el colectivo de trabajadoras, la falta de prórroga o finalización de los contratos de duración determinada. La importancia de esta omisión es enorme si tenemos en cuenta la elevada tasa de temporalidad que sufre el colectivo de trabajadoras, agravada por el hecho de la materni$\mathrm{dad}^{48}$. Así pues, se producen un significativo número de situaciones en que el empresario, o extingue, o bien no prorroga el contrato de trabajo; o pone fin al mismo durante el período de prueba. La jurisprudencia de suplicación de los últimos diez años se ha hecho eco de estas circunstancias y ha puesto de manifiesto, en reiteradas ocasiones, que cuando el embarazo o el disfrute de la licencia por maternidad coinciden con la terminación del contrato, se produce el momento de mayor conflictividad para la estabilidad en el empleo de la trabajadora ${ }^{49}$

En tales situaciones, si el trabajo es compatible con el embarazo o la

46 G. Tudela Cambronero, (1988), p. 47; J. C. Arce, (1997), p. 25.

47 E. Ortega Prieto, (1995), p. 61.

48 R. Escudero Rodríguez, (1994), p. 261.

49 Por todas, STSJ del País Vasco de 23-2-1998, STSJ de Cataluña de 16-10-1997 y STSJ de 19-3-1996. 
maternidad, la falta de contratación provoca una discriminación por razón de sexo, incluso cuando el estado de la mujer exija dispensa de trabajo o implique traslado; también, por ser el embarazo una situación temporal y que solo sufren las mujeres, debiendo el empresario proceder a su contratación o renovación. De nuevo, nos encontraríamos ante una situación que perjudica a las mujeres por su condición femenina, y que, en definitiva entorpece la continuidad de la carrera profesional dificultando su acceso al empleo ${ }^{50}$. Desde nuestro punto de vista y para concluir, la solución vendría dada por considerar que, a pesar de la omisión de la norma, la falta de continuidad de un contrato temporal durante el transcurso de alguna de las situaciones protegidas (embarazo, suspensión por riesgo durante el embarazo, suspensión por maternidad, excedencia por cuidados de hijos...) podría encajar en la categoría de los despidos "nulos cualificados". Si así pudiera considerarse, la trabajadora disfrutaría de una presunción automática de nulidad por la sola acreditación de encontrase en alguna de las situaciones referidas sin necesidad por su parte de probar indicios de discriminación.

\section{Conclusión}

Desde sus orígenes, en 1900, el Derecho del trabajo ha mostrado una preocupación constante para posibilitar el equilibrio entre vida profesional y familiar. La mayor parte de las medidas adoptadas para su promoción hasta 1989 ( permisos, suspensiones de contrato, reducciones de jornada, excedencias) estaban, principalmente, dirigidas a la protección de la maternidad de la trabajadora; la reforma de 1989 marca un punto de inflexión, al reconocer como copartícipe de algunas de estas medias al padre, de esta forma se amplía la protección a toda familia y se incide positivamente en la estabilidad en el empleo de la trabajadora, permitiendo que la mujer se reincorpore al trabajo sin desatender el cuidado del hijo, cuando se ponga en riesgo la continuidad de su vida profesional. Ahora bien, son inexistentes hasta la promulgación de la Ley 39/99 de conciliación de la vida laboral y profesional las medidas específicas de protección frente a la ruptura injustificada del contrato de los trabajadores, hombres y mujeres, durante el ejercicio de sus responsabilidades familiares. A partir de dicha regulación el legislador incorpora, por influjo de la normativa internacional, la protección más especializada y adecuada para la estabilidad en el empleo de los trabajadores

50 R. Molina González-Pumariega, (2000). 
con responsabilidades familiares que ha existido hasta el momento en el ordenamiento laboral, consistente en la presunción de nulidad de los despidos producidos durante el ejercicio de dichas responsabilidades.

\section{Bibliografía}

Albiol Montesinos, l., (1981), "Resolución voluntaria del contrato por matrimonio", Rev. Seguridad Social, no 9, pp. 57-64.

Alonso Olea, M., (1961), "La Ley de 22 de julio de 1961 sobre derechos políticos, profesionales y de trabajo de la mujer", Rev. de Administración Pública, no 36, pp. 327-354.

ARCE, J. C., (1971), La extinción objetiva del contrato. Despido por causas económicas y despidos colectivos, Granada, Ed. Comares.

Bayón Chacón, G. y Pérez Botija, E., (1961), Manual de Derecho del Trabajo, Madrid.

Capel Martínez, R., (1999), Mujer y trabajo en el siglo XX, Madrid, Cuadernos de Historia.

Cardona Rubert, B., (2001), “Despido de trabajadora embarazada como manifestación de discriminación directa por razón de sexo", Aranzadi Social, 21, pp. 1-12.

Charro Baena, P. y Herraiz Martín, S., (1998), "Las responsabilidades familiares y el contrato de trabajo. Notas críticas y propuestas", Aranzadi Social, vol. V, pp. 533-570.

CRUz Villalón, J., (1999), “El fomento de la integración plena y estable de la mujer en el trabajo asalariado, (comentario a la Ley para promover la conciliación de la vida familiar y laboral de las personas trabajadoras)", Rev. Mo Trabajo y Asuntos Sociales, № 1 extraord., pp. 71-102.

_, (coord.), (1997), La igualdad de trato en el Derecho comunitario, Pamplona, Aranzadi.

DURÁn LóPEZ, F., (1987), "Análisis de la regulación jurídico-positiva del despido colectivo en España", Documentación Laboral n²2, pp. 40-61.

Escudero Rodríguez, R., (1989), “La Ley 3/1989. Una reforma promocional de la mujer con acentuados claroscuros", Relaciones Laborales, no 11, pp. 11411166. 
- , (1994), "La aplicación de la directiva 92/85 en España” en La igualdad de trato en el Derecho Comunitario Laboral, (Villalón dir.), Pamplona, Aranzadi.

FeRnÁndez López, Mạ F., (1993), "La discriminación en la jurisprudencia constitucional", Relaciones Laborales, tomo I, pp. 151-178.

González Castro, J., (1914) El trabajo de la mujer en la industria, Madrid, Instituto de Reformas Sociales.

Gorell Hernández, J., (1999), "La reciente Ley 39/1999, para promover la conciliación de la vida familiar y laboral de las personas trabajadoras", Relaciones Laborales, tomo II, pp. 10-53.

López Álvarez, M. J ., (2000), "Responsabilidades familiares en el marco del contrato de trabajo: orígenes y antecedentes de su regulación normativa", Rev. ICADE, no 51, septiembre-diciembre, pp. 127-158.

López Álvarez, M. J . y Núñez-Cortés Contreras, P., (2003), "La Incidencia de las responsabilidades familiares en el contrato de trabajo", en Familia y Trabajo, Madrid, Instituto de la Familia, Universidad Pontificia Comillas, pp. 83-105.

Marvaud, A., (1975), "La cuestión social en España", Revista de Trabajo, Madrid, pp. 240-261.

Molina González-Pumariega, R., (2000), "El permiso parental por maternidad y la protección frente al despido tras la Ley 39/99", Aranzadi Social, Vol. V, pp. 256-270.

Molero Manglano, C., (1999) "100 años de Derecho del Trabajo", Rev. ICADE, no 46, pp. 105-146.

Monereo Pérez, J.A. y Fernández Avilés, A., (1997), El despido Colectivo en el Derecho Español, Pamplona, Ed. Aranzadi.

Montalvo Correa, J., (1975), Fundamentos de Derecho del Trabajo, Madrid, Civitas.

Navarro Nieto, F., (1996), Los despidos colectivos, Madrid, Ed. Civitas.

Nevado Fernández, Ma J., (2000), "El cuidado legal de personas a cargo de trabajadores", Rev. Española de Derecho del Trabajo, no 101, pp. 365-392.

Núñez-Cortés Contreras, P., (2002), La licencia por maternidad de la trabajadora, Madrid, Dykinson. 
-, (2000) , “La configuración jurídica del despido en la Ley de Conciliación del Trabajo y la Vida Familiar", Rev. ICADE, no 51, septiembre-diciembre, pp. 171-184.

-, (2002), "Los orígenes de la protección por maternidad", Revista de Fomento Social, (enero-marzo), pp. 25-42.

Ortega Prieto, E., (1995), La extinción de la relación laboral por amortización del puesto de trabajo, Barcelona, Ed. Praxis.

Palomeque López, M. C., (1975-1976), “Orígenes de la regulación del trabajo femenino en España: la Ley de 13 de marzo de 1900", Cuadernos de Derecho del Trabajo, no 1-2, pp. 260-275.

Rodriguez-Piñero, M., (1993), “Discriminaciones e igualdad entre los sexos en la relación de trabajo", Relaciones Laborales, tomo I, pp. 19-25.

Sala Franco, T., (1992), "Trabajadores con responsabilidades familiares y contrato de trabajo", Tribuna. Social, no 14, pp. 7-12.

Sempere Navarro, A., (1989), "La Ley 3/1989, sobre maternidad e igualdad de trato de la mujer trabajadora. Nota crítica", Relaciones Laborales, no 13, pp. 85-97.

Tudela Cambronero, G., (1988), Las garantías de los representantes de los trabajadores en la empresa, Madrid, Ed. Tecnos.

Velasco Portero, T., (2002), "Incidencia de la vida familiar sobre el contrato de trabajo", Revista de Fomento Social no 225, (enero-marzo), pp. 43-64. 